\title{
Routinely available biomarkers as long-term predictors of heart failure in patients with single-vessel disease, completely revascularized acute ST-segment elevation myocardial infarction: a follow-up study
}

\author{
Ivan Zeljković*, Šime Manola, Vjekoslav Radelfić \\ University Hospital Centre Sestre milosrdnice, Zagreb, Croatia
}

Aim: To assess the efficacy of high sensitive C-reactive protein (hsCRP), cardiac troponin $\mathrm{T}$ (cTnT) and creatin kinase (CK) as long-term predictors of heart failure in patients with acute ST-segment elevation myocardial infarction (STEMI) who underwent primary percutaneous coronary intervention ( $\mathrm{pPCl}$ ) with successful and complete revascularization and to compare their predictive value with B-type natriuretic peptide predictive value.

Patients and Methods: This prospective study evaluated 47 patients with acute STEMI who had normal left ventricular ejection fraction (LVEF) (50\%) at admittance and underwent complete revascularization. Blood samples were collected from admission to the day 7 . The primary endpoint was the reduction of LVEF $<50 \%$ after 12 months.

Received: $29^{\text {th }}$ Apr 2014

*Address for correspondence: Klinički bolnički centar Sestre milosrdnice, Vinogradska 29, HR-10000 Zagreb, Croatia.

Phone: 385-91-782-32-89

E-mail: ivanzeljkov@gmail.com
Results: Patients who reached primary endpoint had significantly higher mean values of cTnT after $24 \mathrm{~h}$ (5.11 vs 2.82 $\mu \mathrm{g} / \mathrm{L} ; \mathrm{p}=0.0101)$ and peak values of CK (3375.5 vs 1865 $\mathrm{U} / \mathrm{L}, \mathrm{p}=0.0084$ ). Equally, the patients with cTnT after $24 \mathrm{~h} \mathrm{Q} 4$ when compared to the ones with Q1Q3 were 6 times more likely to develop LVEF <50\% (OR 6.27, 95\% Cl 1.35-29.06, $\mathrm{p}=0.0200$ ). Regarding hsCRP, there was no significant relation between hsCRP and development of primary end-point, neither when the values are dichotomized at a cut-off limit of $\geq 11 \mathrm{mg} / \mathrm{l}(\mathrm{p}=0.5410)$ nor when they are split into quartiles $(p=0.8482)$.

Conclusion: cTnT and CK could serve as predictors of reduced LVEF in patients with acute STEMI who had normal systolic function at admission, single-vessel disease, and were successfully revascularized during the primary $\mathrm{PCl}$. However, BNP showed to be a more powerful predictor in this low-risk population, even more powerful than the multimarker score we designed.

KEYWORDS: ST-segment elevation myocardial infarction, biomarkers, long-term, prognosis, heart failure.

CITATION: Cardiol Croat. 2014;9(5-6):231.

\section{Literature}

1. Wang TJ, Gona P, Larson MG, et al. Multiple biomarkers for the prediction of first major cardiovascular events and death. N Engl JMed. 2006;355:2631-9.

2. Mega JL, Brügger-Andersen T, Aarsetoy $\mathrm{H}$, et al. The long-term prognostic value of multiple biomarkers following a myocardial infarction. Thromb Res. 2008;123:60-6.

3. Roubille F, Samri A, Cornillet L, et al. Routinely-feasible multiple biomarkers score to predict prognosis after revascularized STEMI. Eur J Intern Med. 2010;21:131-6. 